\title{
Severe traumatic brain injury in New South Wales: comparable outcomes for rural and urban residents
}

\author{
Peter G Harradine, Julie B Winstanley, Robyn Tate, Ian D Cameron, lan J Baguley and Ross D Harris
}

M ost research on the variables which influence rehabilitation outcomes after traumatic brain injury (TBI) has focused on injury severity, and little is known about the effect of environmental barriers, such as rurality and geographical remoteness. There are important differences in the incidence and mortality from TBI and availability of rehabilitation resources between urban and rural areas. Residents of rural areas have a higher incidence of and mortality from TBI than residents of urban areas, but they have poorer access to specialist brain injury rehabilitation resources. ${ }^{1-4}$

Research has only recently focused on the issues associated with rehabilitation after TBI in rural areas. One North American study which examined a region without an organised statewide trauma care delivery system or brain injury program found that survivors of TBI in rural areas were more likely to be functionally dependent and report worse health 18 months after injury than TBI survivors in urban areas. ${ }^{5}$ Rural survivors of TBI often need to travel long distances to use hospital-based rehabilitation services and programs, ${ }^{3-5}$ suggesting that environmental barriers, such as rurality, should be considered in TBI outcomes.

In New South Wales, about $65 \%$ of fatalities from road trauma occur in rural areas, where $30 \%$ of the population lives. ${ }^{6}$ Studies have shown good concordance between place of trauma and place of residence of injured patients. ${ }^{1,2}$ NSW has a critical care network, better developed in some areas of the state than others, to assist in early retrieval of seriously injured patients to rural base hospital intensive care units and to urban neurosurgical units when required.

\section{ABSTRACT}

Objective: To compare differences in functional outcomes between urban and rural patients with traumatic brain injury (TBI).

Design: A longitudinal, prospective, multicentre study of a 2-year cohort from the Brain Injury Rehabilitation Program (BIRP) for New South Wales, with follow-up at 18 months after injury.

Participants: 198 patients (147 urban, 51 rural) with severe TBI from the 11 participating rehabilitation units.

Main outcome measures: Demographic and injury details collected prospectively using a standardised questionnaire, and measures from five validated instruments (Disability Rating Scale, Mayo-Portland Adaptability Inventory, Sydney Psychosocial Reintegration Scale, Medical Outcomes Study Short Form and the General Health Questionnaire - 28-item version) administered at follow-up to document functional, psychosocial, emotional and vocational outcomes.

Results: Demographic details, injury severity, lengths of stay in intensive and acute care wards were similar for both rural and urban groups. There were no significant group differences in functional outcomes, including return to work, at follow-up.

Conclusions: Our findings contrast with previous research that has reported poorer outcomes after TBI for rural residents, and suggest that the integrated network of inpatient, outpatient and outreach services provided throughout NSW through the BIRP provides effective rehabilitation for people with severe TBI regardless of where they live.

MJA 2004; 181: 130-134
The Brain Injury Rehabilitation Program (BIRP) for NSW is unique in that there is an extensive statewide network of services. There are three specialised adult inpatient brain injury units in the capital, Sydney, and eight regional brain injury rehabilitation programs, including two in the metropolitan centres of Wollongong and Newcastle. The rural units often have access to generic inpatient rehabilitation beds, but their emphasis is generally on rehabilitation and community integration through transitional living units (TLUs), and outpatient and outreach services. Access to psychiatric and psychological resources is quite limited in
New England Brain Injury Rehabilitation Program, Tamworth Base Hospital, Tamworth, NSW.

Peter G Harradine, MB BS, FAFRM (RACP), Director of Rehabilitation and Aged Care Service. Rehabilitation Studies Unit, Faculty of Medicine, University of Sydney, Sydney, NSW.

Julie B Winstanley, PhD, CStat, Senior Research Fellow and Statistician; Robyn Tate, MPsychol, PhD, Associate Professor; Ian D Cameron, MB BS, PhD, Motor Accidents Authority of NSW

Associate Professor of Rehabilitation Medicine.

Brain Injury Rehabilitation Service, Westmead Hospital, Westmead, NSW.

Ian J Baguley, MB BS, FAFRM, Research Team Leader.

Pain Management and Research Centre, University of Sydney, St Leonards, NSW.

Ross D Harris, PhD, MA, Professor.

Reprints will not be available from the authors. Correspondence: Dr Julie B Winstanley,

Rehabilitation Studies Unit, Faculty of Medicine, University of Sydney, PO Box 6, Ryde, NSW 1680.

jwin6139@mail.usyd.edu.au rural areas, ${ }^{7}$ and this can lead to difficulties dealing with the ongoing challenging behaviours and cognitive impairment that may result from TBI.

Our aim was to compare the outcomes of rural and urban NSW residents who had had severe TBI.

\section{METHODS}

The methods of this study have been described in detail (Associate Professor $\mathrm{R}$ Tate, Rehabilitation Studies Unit, Faculty of Medicine, University of Sydney, personal communication). A range of demographic, preinjury and postinjury details, and outcome measurements were examined at rehabilitation admission and at 18-month follow-up for urban and rural NSW residents.

Participants were all eligible patients admitted to any of the 11 participating adult units of the BIRP between 1 October 1999 and 30 September 2001. Selection criteria were age 16-65 years, more than 7 days' post-traumatic amnesia (PTA), and de-novo TBI in the previous 6 months. Participants were excluded if there was no person availa- 
ble to give informed consent, or if they had had previous TBI or other acquired brain injury, or had a past medical history likely to affect recovery.

The Accessibility/Remoteness Index of Australia (ARIA) ${ }^{8}$ was used to classify participants into two groups according to their residential postcode at the time they were injured. These groups were:

- Urban - relatively unrestricted accessibility of goods, services and opportunities for social interaction $\left(\mathrm{ARIA}^{8}\right)$, which is in concordance with Rural, Remote and Metropolitan Areas classification (RRMA) ${ }^{9}$ categories 1 and 2 (ie, capital city and other metropolitan areas); and

- Rural - some significant restrictions to accessibility of some goods, services and opportunities for social interaction (ARIA), which is in concordance with RRMA categories 3-7 (ie, areas with an urban centre with a population of less than 100000 ).

\section{Outcome measures}

We report five outcome measures, examining disability, impairments, participation, quality of life, emotional functioning and vocational outcome. Overall level of functioning was rated by the clinician using the Disability Rating Scale (DRS), ${ }^{10}$ an 8-item scale measuring basic functioning, daily activities and psychosocial functions. Scores range from 0 to 30 , with higher scores indicating greater disablement. Levels of impairment and activity limitation were documented using the Mayo-Portland Adaptability Inventory (MPAI), ${ }^{11}$ also rated by a clinician. This 30-item instrument initially examines impairments and activities in six domains; these were summarised into two composite scores measuring cognitive and non-cognitive impairment.

Participation restriction was examined at follow-up using the Sydney Psychosocial Reintegration Scale (SPRS), ${ }^{12}$ rated by a close relative. The SPRS is a 12 -item scale sampling three domains (occupational activity, interpersonal relationships, and independent living skills). Total scores range from 0 to 72, with higher scores indicating higher levels of psychosocial reintegration.

Level of emotional functioning was selfrated by patients, using the General Health Questionnaire, 28-item version (GHQ-28); this measures four domains — somatic symptoms, anxiety, social dysfunction and depression. This was analysed as a total GHQ score, and categorically as numbers of patients above the threshold score of 4 (an

1 Demographic, injury and rehabilitation details, by area group

\begin{tabular}{|c|c|c|c|}
\hline & $\begin{array}{l}\text { Urban } \\
(n=147)\end{array}$ & $\begin{array}{c}\text { Rural } \\
(n=51)\end{array}$ & $\begin{array}{l}\text { Difference } \\
(95 \% \mathrm{Cl})\end{array}$ \\
\hline Sex & & & $5 \%(-7 \%$ to $20 \%)$ \\
\hline Male & 117 (80\%) & $38(75 \%)$ & \\
\hline Female & $30(20 \%)$ & $13(25 \%)$ & \\
\hline Mean age (years [SD]) & $32.1(12.2)$ & $32.1(13.8)$ & $0.0(-4.05$ to 4.05$)$ \\
\hline \multicolumn{4}{|l|}{ Level of education } \\
\hline Some high school education & $75(53 \%)$ & $29(57 \%)$ & $4 \%(-19 \%$ to $11 \%)$ \\
\hline Year 12 completed & $19(13 \%)$ & $3(6 \%)$ & $7 \%(-4 \%$ to $15 \%)$ \\
\hline TAFE/University & $13(9 \%)$ & $6(12 \%)$ & $3 \%(-15 \%$ to $6 \%)$ \\
\hline Graduate & $36(25 \%)$ & $13(25 \%)$ & $0 \%(-15 \%$ to $12 \%)$ \\
\hline \multicolumn{4}{|l|}{ Employment status (preinjury) } \\
\hline Full- or part-time employed & $102(69 \%)$ & $33(65 \%)$ & $5 \%(-9 \%$ to $2 \%)$ \\
\hline Student & $16(11 \%)$ & $7(14 \%)$ & $3 \%(-16 \%$ to $6 \%)$ \\
\hline Unemployed & $21(14 \%)$ & $9(17 \%)$ & $-3 \%(-17 \%$ to $7 \%)$ \\
\hline Other & $8(5 \%)$ & $2(4 \%)$ & $2 \%(-8 \%$ to $7 \%)$ \\
\hline \multicolumn{4}{|l|}{ Cause of injury } \\
\hline Transport-related & $91(62 \%)$ & 34 (67\%) & $-5 \%(-19 \%$ to $11 \%)$ \\
\hline Fall & $30(20 \%)$ & $10(20 \%)$ & $-1 \%(-13 \%$ to $12 \%)$ \\
\hline Assault & $18(12 \%)$ & $5(10 \%)$ & $2 \%(-10 \%$ to $11 \%)$ \\
\hline Other & $8(5 \%)$ & $2(4 \%)$ & $2 \%(-8 \%$ to $7 \%)$ \\
\hline Median GCS (lowest score) (range) & $6.5(3-15)$ & $6(3-15)$ & $0(0$ to 1$)$ \\
\hline \multicolumn{4}{|l|}{ Median number of days: } \\
\hline In intensive care (range) & $10(0-41)$ & $10(0-49)$ & $0(-3$ to 3$)$ \\
\hline In an acute care ward (range) & $14(0-119)$ & $15.5(7-84)$ & $-4(-8$ to 0$)$ \\
\hline Of PTA (range) & $29(7-182)$ & $22(7-182)$ & $6(-1$ to 12$)$ \\
\hline From injury to admission & $28(0-243)$ & $36(0-203)$ & $-5(-14$ to 3$)$ \\
\hline \multicolumn{4}{|l|}{ Rehabilitation type } \\
\hline Inpatient & $94(64 \%)$ & $20(39 \%)$ & $25 \%$ (9\% to $39 \%)$ \\
\hline Transitional living unit & $20(14 \%)$ & $11(22 \%)$ & $-8 \%(-22 \%$ to $3 \%)$ \\
\hline Outreach/Community & $13(9 \%)$ & $11(22 \%)$ & $-13 \%(-26 \%$ to $-2 \%)$ \\
\hline Outpatient & $16(11 \%)$ & $5(10 \%)$ & $1 \%(-11 \%$ to $9 \%)$ \\
\hline Generic bed & $4(3 \%)$ & $4(8 \%)$ & $-5 \%(-16 \%$ to $1 \%)$ \\
\hline Rehabilitation prior to being admitted to BIRP & $41(28 \%)$ & $18(35 \%)$ & $-7 \%(-23 \%$ to $7 \%)$ \\
\hline
\end{tabular}

TAFE = technical and further education; GCS = Glasgow Coma Score; PTA = post-traumatic amnesia; $\mathrm{BIRP}=$ Brain Injury Rehabilitation Program.

For categorical variables, differences in proportions presented as percentages with $95 \% \mathrm{Cls}$ and subject to rounding error for small sample sizes. For continuous variables, mean or median differences are presented with $95 \%$ Cls.

indicator of a level of emotional functioning which may require clinical intervention, referred to as "caseness"). ${ }^{13}$ Patients also completed the short-form health survey developed for the Medical Outcomes Study (the SF36) to measure quality of life, scored separately for mental and physical components and standardised to the Australian population. ${ }^{14}$ Additional information on current employment status, living arrangements and compensation was obtained from a structured questionnaire.

\section{Statistical analysis}

Analyses were performed using a standard statistical package (SPSS Version 10). ${ }^{15}$ Group differences for categorical variables were analysed by $\chi^{2}$ tests (group sizes permitting, Cochran's relaxed rule). For all subscale scores, except the norm-based SF36 component scores, between-group differences were analysed with Mann-Whitney $U$ tests, with reduced level of significance $(P=0.01)$, and differences over time with Wilcoxon's matched-pairs signed-ranks 


\begin{tabular}{|c|c|c|c|}
\hline $\begin{array}{l}\text { Outcome measures at } \\
18 \text {-month follow-up }\end{array}$ & $\begin{array}{l}\text { Urban } \\
(n=109)\end{array}$ & $\begin{array}{c}\text { Rural } \\
(n=35)\end{array}$ & $\begin{array}{l}\text { Median difference } \\
(95 \% \mathrm{Cl})\end{array}$ \\
\hline \multicolumn{4}{|l|}{ Clinician rated } \\
\hline Median DRS (range) & $4(0-26)$ & $4(0-13)$ & $0(1$ to 1$)$ \\
\hline \multicolumn{4}{|l|}{ Median MPAI (range) } \\
\hline Cognitive total & $6(0-18)$ & $7(0-12)$ & $0(-1$ to 1$)$ \\
\hline Non-cognitive total & $17(0-42)$ & $17(0-39)$ & $0(-4$ to 5$)$ \\
\hline Overall total & $25(0-60)$ & $21(2-51)$ & $0(-6$ to 6$)$ \\
\hline \multicolumn{4}{|l|}{ Patient rated } \\
\hline \multicolumn{4}{|l|}{ Median SPRS (range) } \\
\hline Total score & $48.5(11-72)$ & $47(1-72)$ & $2(-5$ to 9$)$ \\
\hline \multicolumn{4}{|l|}{ Median GHO 28 (range) } \\
\hline Total score (GHQ method) & $5(0-27)$ & $6(0-25)$ & $-1(-3$ to 1$)$ \\
\hline \multicolumn{4}{|l|}{ Mean SF36 (SD) } \\
\hline Physical component score* & $44.3(11.9)$ & $45.3(11.3)$ & $-1.0(-5.6$ to 3.6$)$ \\
\hline Mental component score* & $45.1(14.5)$ & $40.1(15.7)$ & $5.0(-0.8$ to 10.7$)$ \\
\hline
\end{tabular}

DRS = Disability Rating Scale; MPAI = Mayo-Portland Adaptability Inventory; SPRS = Sydney Psychosocial Reintegration Scale; GHQ = General Health Questionnaire; SF36= Short Form 36 Questionnaire.

* Mean and standard deviations standardised using Australian normative data for SF36 from the 1995 census (Australian Bureau of Statistics). tests. ${ }^{16}$ Medians, ranges and $95 \%$ confidence intervals around the median are presented for these measures owing to the high degree of skewness.

The standardised SF36 Physical Component Score (PCS) and Mental Component Score (MCS) are widely accepted to be normally distributed. ${ }^{17}$ Means, standard deviations and 95\% confidence intervals around the mean are presented for ease of interpretation and comparison with existing published data. Post-hoc power analysis, to detect group differences of half a standard deviation in the SF36 component scores, was conducted to obtain an estimate of the statistical power of the study. A two-group $t$
3 Living arrangements and work status pre-injury and at 18-month follow-up

\begin{tabular}{|c|c|c|c|c|c|}
\hline & \multicolumn{2}{|c|}{ Urban $(n=109)$} & \multicolumn{2}{|c|}{ Rural $(n=35)$} & \multirow{2}{*}{$\begin{array}{l}\text { Differences* } \\
\text { between urban and } \\
\text { rural at } 18 \text { months } \\
(95 \% \mathrm{Cl})\end{array}$} \\
\hline & Pre-injury & 18 months & Pre-injury & 18 months & \\
\hline \multicolumn{6}{|l|}{ Living arrangements } \\
\hline Total in private home & 107 (98\%) & 101 (93\%) & 34 (97\%) & $32(91 \%)$ & $1 \%(-7 \%$ to $15 \%)$ \\
\hline Alone & $12(11 \%)$ & $7(7 \%)$ & $4(12 \%)$ & $3(9 \%)$ & $-2 \%(-16 \%$ to $6 \%)$ \\
\hline With parents & 40 (37\%) & $41(41 \%)$ & 9 (27\%) & $12(38 \%)$ & $3 \%(-15 \%$ to $20 \%)$ \\
\hline With spouse/de facto & 39 (36\%) & 44 (44\%) & $13(38 \%)$ & 15 (47\%) & $-2 \%(-21 \%$ to $15 \%)$ \\
\hline Other & $16(15 \%)$ & $9(9 \%)$ & $8(24 \%)$ & $2(6 \%)$ & $3 \%(-11 \%$ to $10 \%)$ \\
\hline Boarding house/other & $2(2 \%)$ & $1(1 \%)$ & $1(3 \%)$ & 0 & $1 \%(-9 \%$ to $5 \%)$ \\
\hline Nursing home & - & $3(3 \%)$ & - & $1(3 \%)$ & $0 \%(-12 \%$ to $5 \%)$ \\
\hline Rehabilitation facility & - & $4(4 \%)$ & - & $2(6 \%)$ & $-2 \%(-15 \%$ to $5 \%)$ \\
\hline \multicolumn{6}{|l|}{ Work status } \\
\hline Working (FT or PT) & 79 (72\%) & $33(30 \%)$ & $23(66 \%)$ & $14(40 \%)$ & $-10 \%(-28 \%$ to $7 \%)$ \\
\hline Unemployed & $12(11 \%)$ & $15(14 \%)$ & $6(17 \%)$ & $3(9 \%)$ & $5 \%(-10 \%$ to $15 \%)$ \\
\hline Student/other & $18(17 \%)$ & $15(14 \%)$ & $6(17 \%)$ & $3(9 \%)$ & $5 \%(-10 \%$ to $15 \%)$ \\
\hline Disability retirement & - & $46(42 \%)$ & - & $15(43 \%)$ & $-1 \%(-19 \%$ to $17 \%)$ \\
\hline
\end{tabular}

$\mathrm{FT}=$ full time; $\mathrm{PT}=$ part time. ${ }^{*}$ Differences subject to rounding error for small sample sizes. test for equivalence in means, ${ }^{18}$ adjusted for unequal group sizes, was used, adopting the alternative hypothesis that the means were equivalent (mean difference, 0 ).

\section{RESULTS}

One hundred and ninety-eight patients with severe TBI were recruited to the study, representing about $55 \%$ of all eligible participants in the program. At rehabilitation admission, 147 (74\%) lived in urban areas and 51 (26\%) lived in rural areas. Among the rural group, 47 had "some" and 4 had "significant" restrictions to accessibility (ie, they lived in remote areas with limited accessibility of some goods, services and opportunities for social interaction). One hundred and forty-four of the 198 participants (109 [76\%] urban and 35 [24\%] rural) were followed up. There were no significant group differences with respect to age, sex or rurality between those who were and were not followed up.

\section{Injury severity and sociodemographic characteristics}

Box 1 includes the demographic characteristics of urban and rural patients at rehabilitation admission, and shows there were no statistically significant differences between the groups. There were seven Aboriginal patients ( 4 urban, 3 rural) and 14 patients from non-English-speaking backgrounds (13 urban, 1 rural).

Cause of injury did not differ between groups (Box 1); over $60 \%$ of injuries were transport-related. There were no differences in the numbers of other associated injuries, including amputation, fractures, peripheralor cranial-nerve injuries. Injury severity was also similar between groups, with no statistically significant differences in lowest Glasgow Coma Scale (GCS) scores, time in intensive care, time in acute-care ward, or duration of PTA. Available data showed median time to retrieval was longer for the rural group than the urban group (30 min; range, $1 \mathrm{~min}$ to $8 \mathrm{~h} ; n=26 \mathrm{v} 15 \mathrm{~min}$; range, $1 \mathrm{~min}$ to $48 \mathrm{~h} ; n=60 ; P=0.039$ ).

\section{Rehabilitation phase}

Box 1 shows the median number of days from injury to admission to rehabilitation was slightly higher for the rural group, but this was not statistically significant. Grouping the type of rehabilitation into inpatient (specialised TBI inpatient beds and generic rehabilitation beds) and non-inpatient (TLU, outreach/community, outpatient) 
showed a significant difference in type of rehabilitation setting. Fifty-three per cent of rural patients (27) were treated in noninpatient settings, compared with $33 \%$ of urban patients (49) $\left(\chi^{2}=5.4 ; \mathrm{df}=1\right.$; $P=0.02)$.

\section{Functional outcomes}

Matched data at admission and follow-up for 144 residents (109 urban and 35 rural) were analysed for differences over time and between groups. The median DRS score at admission to rehabilitation for the urban group was 7 (range, 0-29), compared with 5 (range, 0-28) for the rural group $(z=2.7$; $P=0.007)$. This indicates that the initial level of disability was greater for the urban group. However, differences between the subscale scores for the MPAI at admission were not statistically significant for the two groups. This may be accounted for by the slightly longer period between injury and admission to the rural units, and increased sensitivity of the DRS when the patient's condition is more severe in the early stages of rehabilitation.

Medians and ranges for all subscale scores and total scores on the outcome measures at follow-up are summarised in Box 2. There were no statistically significant differences in any of the instruments at follow-up. The median DRS score was 4 for both the urban and rural groups, and the MPAI subscales were very similar. Psychosocial outcomes measured by the SPRS for the two groups were also similar. Fifty four (37\%) of the urban group and 17 (33\%) of the rural group recorded GHQ scores above the threshold of 4 , indicating psychiatric "caseness".

On the SF36, the mean PCS was slightly higher and mean MCS slightly lower for the rural group, but the differences were not statistically significant. The standard deviations indicated greater variability than expected, especially for the MCS, in both rural and urban groups. The mean differences for PCS and MCS were 1 and 5 units, respectively, and well within half a standard deviation of the mean.

\section{Living arrangements and vocational outcome}

Most participants had returned to their preinjury living arrangements (Box 3). However, slightly fewer were living alone after 18 months, and more were living with parents (this was more noticeable in the rural group [27\% to $38 \%]$, but was not statistically

4 Rehabilitation and compensation status at admission and 18-month follow-up

\begin{tabular}{|c|c|c|c|c|}
\hline & \multicolumn{2}{|c|}{ Urban $(n=109)$} & \multicolumn{2}{|c|}{ Rural $(n=35)$} \\
\hline & $\begin{array}{l}\text { Rehabilitation } \\
\text { admission }\end{array}$ & $\begin{array}{l}\text { 18-month } \\
\text { follow-up }\end{array}$ & $\begin{array}{l}\text { Rehabilitation } \\
\text { admission }\end{array}$ & $\begin{array}{l}\text { 18-month } \\
\text { follow-up }\end{array}$ \\
\hline \multicolumn{5}{|c|}{ Rehabilitation status } \\
\hline Inpatient & $72(66 \%)$ & $6(6 \%)$ & $16(46 \%)$ & $0(0 \%)$ \\
\hline Non-inpatient & 37 (34\%) & 47 (43\%) & 19 (54\%) & 15 (43\%) \\
\hline Discharged & - & $56(51 \%)$ & - & 20 (57\%) \\
\hline \multicolumn{5}{|c|}{ Compensation status } \\
\hline None & 42 (39\%) & $45(42 \%)$ & $15(43 \%)$ & $18(51 \%)$ \\
\hline Possible claim & 40 (37\%) & $13(12 \%)$ & $12(34 \%)$ & $1(3 \%)$ \\
\hline Liability accepted & $14(13 \%)$ & 42 (39\%) & $4(11 \%)$ & $14(40 \%)$ \\
\hline Settled & $3(3 \%)$ & $3(3 \%)$ & 0 & 0 \\
\hline Other & $10(9 \%)$ & $6(6 \%)$ & $4(11 \%)$ & $2(6 \%)$ \\
\hline
\end{tabular}

significant). A small percentage of participants in both groups were living in a nursing home or rehabilitation facility at 18month follow-up. Matched data on employment status confirmed that a shift in economic status affected patients from both groups equally, with very similar proportions in disability retirement at follow-up.

\section{Rehabilitation and compensation status}

By 18 months after injury, just over half of the participants had been discharged from the program. Six urban participants (6\%) were still receiving inpatient rehabilitation, and the rest were still in contact with the service through outreach or community facilities. Again, percentages for urban and rural residents were comparable (Box 4). Finally, only three compensation claims (2\% of the whole group) were settled by 18month follow-up, all for urban residents.

\section{DISCUSSION}

Our findings indicate that rural NSW residents have similar rehabilitation outcomes to urban residents after severe TBI. By contrast, a study in Iowa, USA, found that a higher proportion of rural residents were dependent in their level of functioning, and reported poorer health. ${ }^{5}$ However, direct comparison with this study is difficult, because it included large numbers of people with mild TBI and used only one item from the DRS level of functioning and one quality-of-life item. Our group was also much more severely injured, with 25\% (37/144) being completely independent at 18 months, compared with $73 \%$ in the Iowa study. Also, Iowa had no organised retrieval system or coordinated brain injury rehabilitation program.

The breadth and detail of the measures used in our study make it the most detailed rural-urban comparison of TBI outcomes to be reported so far, and our findings are strengthened because of its multicentre and prospective design.

We acknowledge that the disparate sample sizes between urban and rural centres increase the risk of type II error and reduce statistical power. However, post-hoc power calculations suggest our study had an estimated power of $71 \%$. The median differences were zero for clinician-rated measures of disability and impairment, with acceptable confidence intervals. The mean group differences for the SF36 component scores were less than five points and, as expected, levels were below expected values (50) for an average adult, ${ }^{17}$ indicating lower-thannormal functioning. The greater variability recorded, especially in the MCS scores, is similar to published norms for other groups of patients with chronic conditions, although there are no normative data for direct comparison for patients recovering from severe TBI. ${ }^{17}$

Challenges remain for rural patients. Those transferred to urban inpatient units may spend many months away from their homes. Appropriate accommodation, social support and financial assistance for carers is essential for maintaining social attachments and interpersonal relationships. Many patients are not compensable (see Box 4) and rely heavily on government-funded schemes, such as the Isolated Patient Transport and Accommodation Assistance 
Scheme, Program for Appliances for Disabled People, and Home and Community Care services.

Managing patients with TBI scattered over vast geographical distances can place considerable strain on healthcare professionals and carers, particularly when behavioural problems arise. Rural healthcare professionals in the BIRP, with local knowledge of available services, are involved in the vocational rehabilitation of TBI patients, enhancing the continuum of care. It is possible that this compensates for the lack of access to jobs in rural areas. It has been reported that a community setting may be a moderator of quality of life after TBI, and that living in a rural area is associated with more openness to seeking social support and a better quality of life compared with living in an urban area. $^{19}$ Rural communities, which are smaller, may provide more stable and supportive interpersonal relationships that shape more positive appraisals of the social environment. However, the problems with recruiting and retaining healthcare professionals in rural areas are well known, and the ability of rural healthcare professionals to deal with complex issues arising from TBI may be limited by time and lack of access to other services, such as psychiatry or psychology. Videoconferencing and other forms of telemedicine can help in this regard. ${ }^{20}$

Given the isolation and resource limitations of rural populations, it is significant that we found comparable outcomes for rural and urban patients after TBI. Several factors may have contributed. The program, as described, is unique in that it provides an extensive integrated network of interdisciplinary services to people with TBI and their families across the state. The program could not function without funding provided by the Motor Accidents Authority of NSW and the NSW Health Department. Patients can remain in or return to their own community at the earliest possible stage of their rehabilitation. The BIRP model would be suitable for adoption in the planning, provision and delivery of other healthcare services.

\section{ACKNOWLEDGEMENTS}

We thank Bridget Myles, research psychologist, for data collection, and the patients and their families for participating in the study. The assistance of clinicians of the units of the NSW Brain Injury Rehabilitation Program is gratefully acknowledged. This study was funded by the New South Wales Motor Accidents Authority, the NSW Department of Health and the Australian Government Department of Health and Aged Care.

\section{COMPETING INTERESTS}

None identified.

\section{REFERENCES}

1 Woodward A, Dorsch MM, Simpson D. Head injuries in country and city. Med J Aust 1984; 141: 13-17.

2 Glabella B, Hoffman R, Marine W, et al. Urban and rural traumatic brain injuries in Colorado. Ann Epidemiol 1997; 7: 207-212.

3 Johnstone B, Nossaman L, Schopp L, et al. Distribution of services and supports for people with traumatic brain injury in rural and urban Missouri. J Rural Health 2002; 18: 109117.

4 Sample P, Darragh A. Perceptives of care access: the experience of rural and urban women following brain injury. Brain Inj 1998; 12: 855-874.

5 Schootman M, Fuortes L. Functional status following traumatic brain injuries: populationbased rural-urban differences. Brain Inj 1999; 13: 995-1004.

6 Doherty S. So this is Christmas. Med J Aust 2001; 175: 585-586

7 The NSW Rural Health Report. The report of the Rural Health Implementation Co-ordination Group - NSW Government Action Plan. Sydney: NSW Health, 2002.

8 Commonwealth Department of Health and Aged Care. Measuring remoteness: Accessibility/Remoteness Index of Australia (ARIA): October 2001 revised edition. Canberra: Department of Health and Aged Care, 2001.

9 Department of Primary Industries and Energy, and Department of Human Services and Health. Rural, Remote and Metropolitan Areas Classification 1991. Census Edition. Canberra: AGPS, 1994.
10 Rappaport M, Hall KM, Hopkins K, Belleza T. Disability rating scale for severe traumatic head trauma: coma to community. Arch Phys Med Rehabil 1982; 63: 118-123.

11 Malec JF, Thompson JM. Relationship of the Mayo-Portland Adaptability Inventory to functional outcome and cognitive performance measures. J Head Trauma Rehabil 1994; 9: 1-15.

12 Tate RL, Hodgkinson AE, Veerabangsa A, et al. Measuring psychosocial recovery after traumatic brain injury: Psychometric properties of a new scale. J Head Trauma Rehabil 1999; 14: 543-557.

13 Goldberg D, Williams P. Users guide to the General Health Questionnaire. Windsor: NFERNelson, 1988.

14 Ware JE Jnr, Sherbourne CD. The MOS ShortForm Health Survey (SF-36). Med Care 1992; 30: 473-483.

15 Norusis M. The Statistical Package for the Social Sciences. Chicago: SPSS, 1986.

16 Siegel S. Nonparametric statistics for the behavioural sciences. London: McGraw Hill, 1956.

17 Ware JE Jnr, Kosinski M. SF36 physical and mental health summary scales: a manual for users of version 1. 2nd ed. Lincoln, Rl: QualityMetric Inc., 2001.

18 Elashoff JD. nQuery advisor version 4.0. User's guide. Los Angeles Cal, 2002.

19 Farmer J, Clark M, Sherman A. Rural versus urban social support seeking as a moderating variable in traumatic brain injury outcome. $J$ Head Trauma Rehabil 2003; 18: 116-127.

20 Schopp L, Johnstone B, Merveille O. Multidimensional telecare strategies for rural residents with brain injury. J Telemed Telecare 2000; 6 Suppl 1: 146-149.

(Received 19 Oct 2003, accepted 17 Feb 2004) 
